\title{
Numerical Assessment of Seepage Control Effects of Underground Powerhouse
}

\author{
Huakang Zheng ${ }^{1, \mathrm{a}}$, Chao $\mathrm{Hu}^{2, \mathrm{~b}}$, Qin Shang ${ }^{1, \mathrm{c}}$ \\ ${ }^{1}$ Changjiang Survey, Planning, Design and Research Co. Ltd., Wuhan 430010, China \\ ${ }^{2}$ Changjiang River Scientific Research Institute of Changjiang Water Resources Commission, \\ Wuhan 430014, China

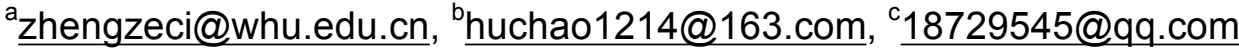

\begin{abstract}
Keywords: underground powerhouse; seepage control; drainage hole array; SVA method; numerical modeling; Yagen II Hydropower Station

Abstract. For performance assessment and optimization design of the seepage control system in the Yagen II underground powerhouse, a numerical method combining a substructure technique, the variational inequality formulation of Signorini's type and an adaptive penalized Heaviside function (short for SVA method) was adopted. Numerical results of seepage flow behavior in the underground powerhouse area of the Yagen II Hydropower Station demonstrate that: (1) the seepage control effects of the layout are very outstanding, and the designed scheme is generally proper and effective; (2) the upper part of the drainage system has little effects in controlling leakage from reservoir, and hence the spacing of the drainage hole arrays at higher elevations can be properly enlarged; (3) the auxiliary drainage hole arrays play an important role in reducing leakage amounts into the underground caverns and pore water pressure in the surrounding rocks, so they are essential for the long-term safe operation of the underground powerhouse.
\end{abstract}

\section{Introduction}

Due to strong permeability of surrounding rock masses and close distance between the underground powerhouse and the reservoir, seepage field in the surrounding rocks of underground powerhouse is one of the most important factors which may affect the safety of hydropower station. In order to reduce seepage flow rate out of the underground opening and improve resistance of the surrounding rocks to seepage failure, a seepage control system including grouting curtains, drainage hole arrays and drainage tunnels is usually designed. For performance assessment and optimization design of the seepage control system, elaborate numerical modeling of the seepage control effects is of vital importance.

For performance assessment and optimization design of the seepage control system, a numerical simulation for the seepage control effects of the seepage control system is needed. For problems with complex seepage control systems, two sources of difficulty are usually encountered in FE numerical simulation: the accurate simulation of seepage field and the simulation of drainage holes. The former involves the determination of free surface. In the literature, the intuitive methods include the residual flow method[1], the adjusting permeability method[2] and the variational inequality method[3] are frequently adopted. The variational inequality formulation of Signorini's type established by Zheng et al.[3] successfully overcomes the singularity at the seepage points and the induced mesh dependency, which has obvious merits for unconfined seepage problems. The latter involves the correct representation of drainage holes and their boundary conditions in the FE model. Among the many methods proposed, only the drainage substructure technique[4] can effectively model the effects of drainage holes, simultaneously with capability in simplifying the generation of FE mesh.

In this study, a method combining the substructure technique, the variational inequality formulation of Signorini's type with the penalized Heaviside function (short for the SVA method)[5] is adopted to assess the performance of the seepage control system in the Yagen II underground powerhouse. The SVA method simplifies the FE mesh of drainage holes, and effectively overcomes the mesh dependency and numerical fluctuations induced by the strong nonlinearity in the determination of free surface. By 
establishing a model of the underground powerhouse area, the rationality and further optimization of seepage control measures are demonstrated, providing reasonable suggestions for the project.

\section{Basic theory for seepage analysis}

According to the Darcy's law and the mass conservation equation, the steady seepage control differential equation is

$$
\frac{\partial}{\partial x_{i}}\left(k_{i j} \frac{\partial h}{\partial x_{j}}\right)=0
$$

where $h$ is the water head and $k_{i j}$ is the second-order hydraulic conductivity tensor. Equation (1) should satisfy the following boundary conditions:

(a) The water head boundary condition

$$
h=\bar{h} \quad\left(\text { on } \Gamma_{\mathrm{h}}\right)
$$

where $\Gamma_{\mathrm{h}}$ is the prescribed water head boundary and $\bar{h}$ is the prescribed water head.

(b) The flux boundary condition

$$
q_{n}=-k_{i j} \frac{\partial h}{\partial x_{i}} n_{j} \quad\left(\text { on } \Gamma_{q}\right)
$$

where $\Gamma_{q}$ is the prescribed flux boundary, $q_{n}$ the flux boundary, and $\boldsymbol{n}$ the outward unit normal vector to the boundary. For an impermeable boundary, $q_{n}=0$.

(c) The free surface boundary condition

$$
h=z, q_{n}=0 \quad\left(\text { on } \Gamma_{\mathrm{f}}\right)
$$

where $\Gamma_{\mathrm{f}}$ is the free surface boundary.

(d) The boundary condition on the seepage surface

$$
h=z, q_{n}=k_{i j} \frac{\partial h}{\partial x_{i}} n_{j}<0 \quad\left(\text { on } \Gamma_{\mathrm{s}}\right)
$$

where $\Gamma_{\mathrm{s}}$ is the seepage boundary.

The problems mentioned above can be solved by the SVA method, and the realization of the algorithm can be referred to the literature[5].

\section{Computational model}

The Yagen II Underground Powerhouse. Located in Yajiang County, Sichuan Province, China, the Yagen II Hydropower Project is the second hydropower cascading project in the middle reach of the Yalong River, with the normal pool level of $2560.0 \mathrm{~m}$ and the regulating storage volume of 16.0 million $\mathrm{m}^{3}$. The water diversion and power generation system consists of diversion tunnels, machine hall, tailrace tunnels and other caverns, with the installed capacity of $1080 \mathrm{MW}$. The designed excavation sizes (length $\times$ width $\times$ height) of three main caverns are as below: $216.80 \mathrm{~m} \times 26.80 \mathrm{~m} \times 67.30 \mathrm{~m}$ (machine hall), $185.10 \mathrm{~m} \times 18.30 \mathrm{~m} \times 22.90 \mathrm{~m}$ (transformer room), $179.00 \mathrm{~m} \times 22.50 \mathrm{~m} \times 77.00 \mathrm{~m}$ (tailrace surge chamber).

The surrounding rocks of underground powerhouse are adamellite with relatively good integrity. Faults and fractures mainly develop in the direction of NE, with the average width of faults below $0.9 \mathrm{~m}$. The seepage control system of underground powerhouse mainly consists of grouting curtains, drainage hole arrays and drainage tunnels. In order to enhance seepage control effects and save engineering quantities, grouting curtains on the left bank of the dam are connected with those of the underground powerhouse. The grouting curtains are settled $50 \mathrm{~m}$ away from the machine hall, parallel with the upstream side of machine hall and extending to the downstream side of tailrace surge chamber. The drainage tunnels are designed with 3 levels: the upper tunnels are located in the top surrounding rocks of machine hall, with floor elevation of $2508.5 \sim 2514.0 \mathrm{~m}$; the middle and lower tunnels are located in the surrounding rocks of machine hall, with floor elevation of $2474.5 \sim 2480.0 \mathrm{~m}$ and $2444.5 \sim 2450.0 \mathrm{~m}$. 
Drainage holes with spacing of $3 \mathrm{~m}$ are designed along with the axis of drainage tunnels. Different levels of drainage tunnels are connected by drainage holes, forming the drainage system. Besides, two layers of assistant drainage hole arrays are designed behind grouting curtains, and three layers of main drainage hole arrays are designed in the surrounding rocks of powerhouse. The seepage control system of the underground powerhouse is illustrated as Fig.1.

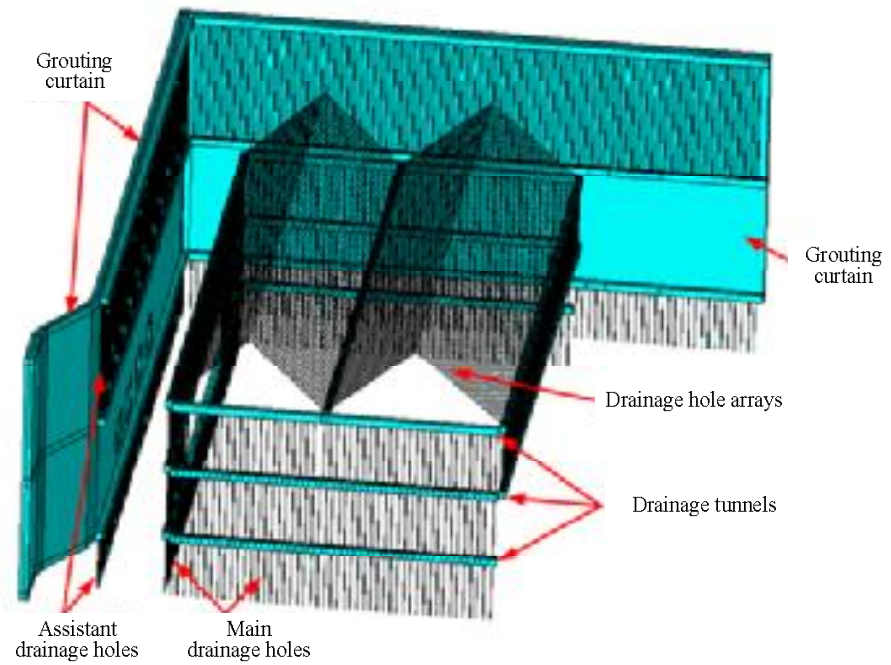

Fig.1 Sketch of seepage control system of the underground powerhouse

FE model. In order to satisfy the requirements of calculation and analysis, three-dimensional FE models of the underground powerhouse area is established, in which the geological conditions and hydraulic structures are strictly modeled. The FE mesh of the underground powerhouse area is shown as Fig. 2, with 1235646 elements and 537394 nodes.

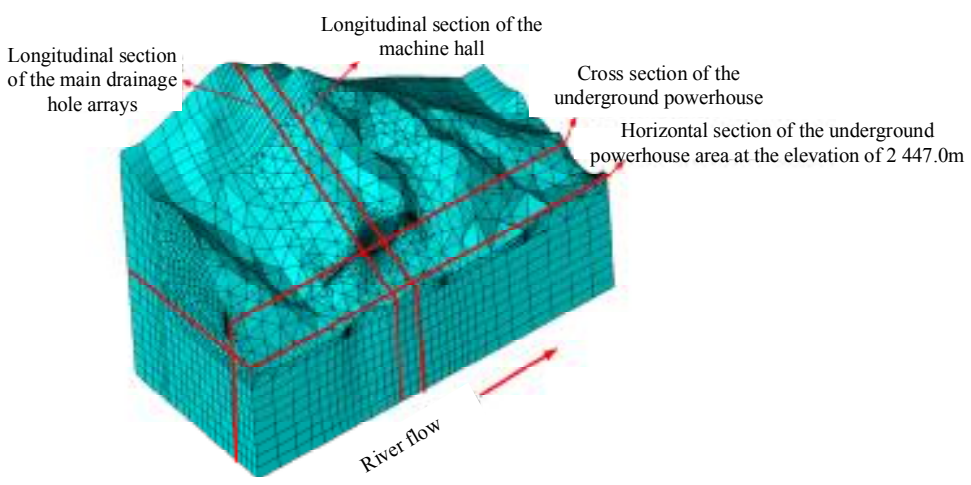

Fig.2 FE meshes of the whole underground powerhouse area

Computational parameters and boundary conditions. According to the geological surveys, the computational parameters of the strata at the underground powerhouse area are shown in Tab.1.

Tab.1 Values of seepage coefficients of different materials

\begin{tabular}{ccccccc}
\hline Materials & $\begin{array}{c}\text { Weak } \\
\text { weathered rocks }\end{array}$ & $\begin{array}{c}\text { Slightly } \\
\text { weathered rocks }\end{array}$ & $\begin{array}{c}\text { Grouting } \\
\text { curtain }\end{array}$ & $\begin{array}{c}\text { Consolidation } \\
\text { grouting }\end{array}$ & $\begin{array}{c}\text { Diversion } \\
\text { tunnel lining }\end{array}$ & $\begin{array}{c}\text { Tailrace } \\
\text { tunnel lining }\end{array}$ \\
\hline $\begin{array}{c}\text { Permeability } \\
(\mathrm{cm} / \mathrm{s})\end{array}$ & $6.0 \times 10^{-5}$ & $2.0 \times 10^{-5}$ & $1.0 \times 10^{-5}$ & $1.0 \times 10^{-5}$ & $1.0 \times 10^{-7}$ & $1.0 \times 10^{-7}$ \\
\hline
\end{tabular}

The boundary conditions are specified as follows: on the upstream submerged surface of the dam and the diversion tunnel surface, the water head is prescribed according to corresponding water level of $2560.0 \mathrm{~m}$; on the downstream submerged surface of the dam and the tailrace tunnel surface, the water head is prescribed according to corresponding water level of $2483.8 \mathrm{~m}$; the left boundary of the model is located in the left-bank mountain, a water level of $2596.0 \mathrm{~m}$ is prescribed on it; the bottom and the upstream and downstream lateral boundaries are assumed to be impermeable; the remaining boundaries, including the ground surfaces above the upstream and downstream water levels, the wall surfaces of 
the machine hall and transformer room, and the boundaries of the drainage tunnels and drainage holes, are all taken as the potential seepage boundaries satisfying the Signorini's complementary condition.

\section{Analysis of computational results}

In the normal operation condition of the reservoir, the water head isolines of the unit cross section of the underground powerhouse are shown as Fig.3. On the upstream side, the seepage free surface drops dramatically at the grouting curtain, passes through the lower drainage tunnel and flows out at the machine hall. On the downstream side, the free surface passes through the tailrace surge chamber, and flows out at the bottom of the machine hall. The transformer room is completely above the free surface, which means no seepage flows through it.

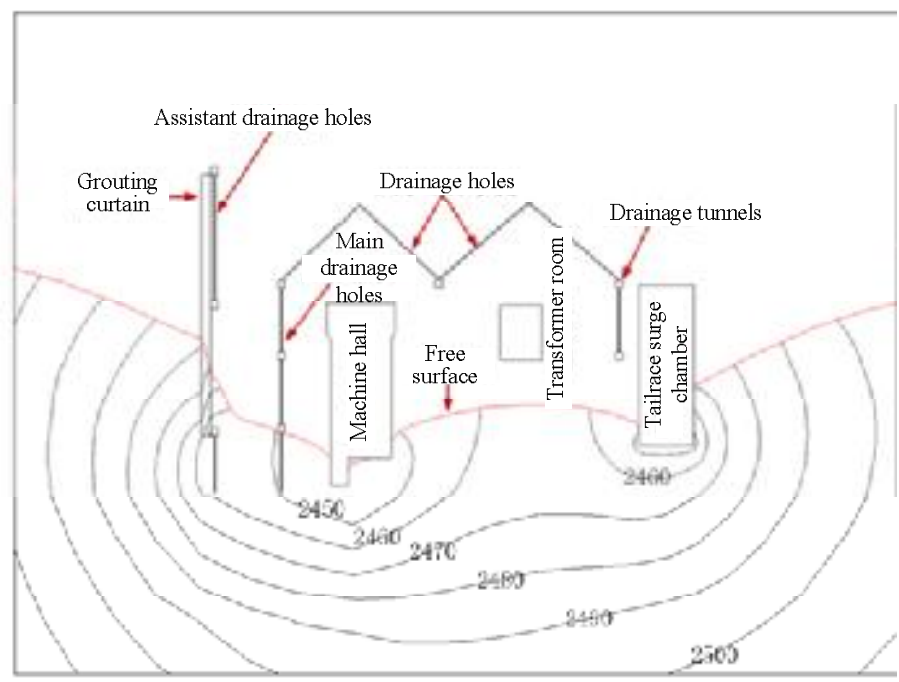

Fig.3 Water head isolines of the unit cross section of the underground powerhouse (unit: $\mathrm{m}$ )

Water head isolines of the longitudinal section of the machine hall are shown as Fig.4. On the side near the mountain, the free surface drops dramatically at the grouting curtain, passes through the lower drainage tunnel, and flows out at the bottom of machine hall. On the side near the river, the free surface passes through the middle drainage hole array, and flows out at the bottom of machine hall.

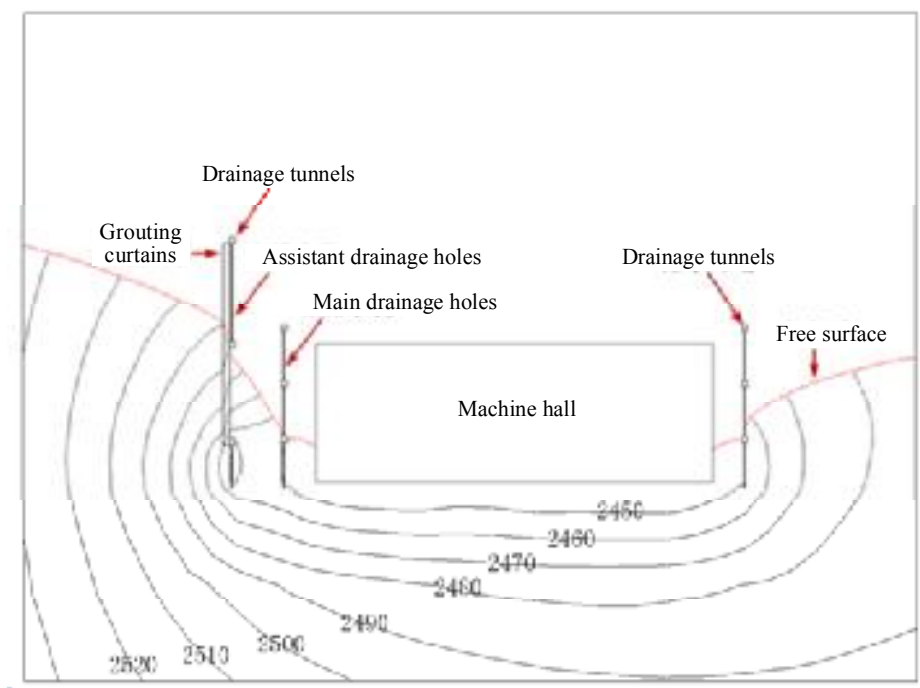

Fig.4 Water head isolines of the longitudinal section of the machine hall (unit: $\mathrm{m}$ )

Pore pressure isolines of the longitudinal section of the main drainage hole arrays are shown as Fig.5. The free surface drops continuously in the surrounding rocks on the left bank side mountain, while the slope is relatively gentle. Nearby the grouting curtain, the slope of free surface becomes more obvious, passing through the bottom of the second level drainage holes and flowing out at the third level drainage tunnel. 


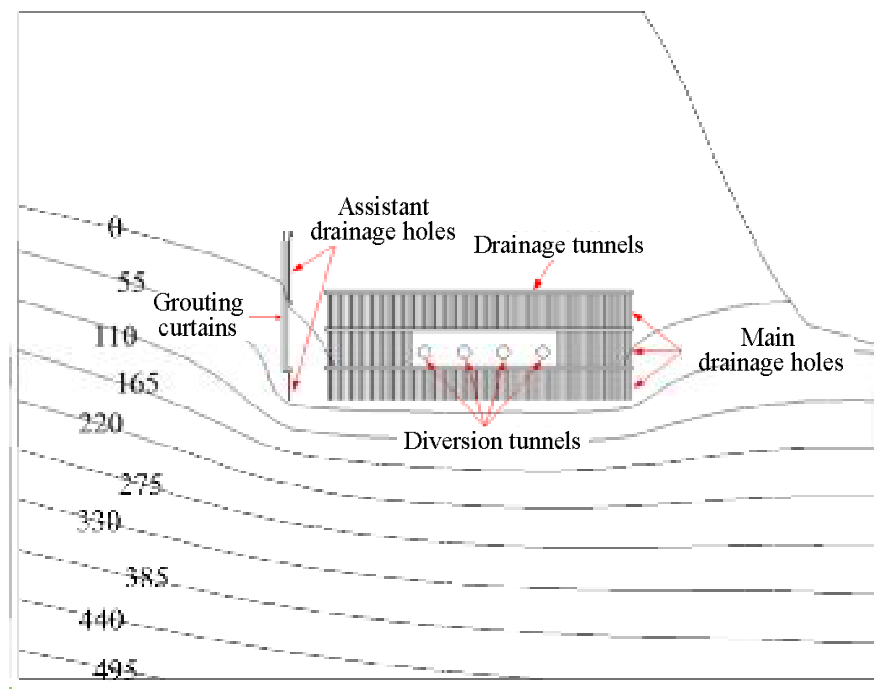

Fig.5 Pore pressure isolines of the longitudinal section of the main drainage hole arrays (unit: $\mathrm{m}$ )

As shown in Fig.3 5, drainage hole arrays can lead to obvious cone of depression of underground water flow in the surrounding rocks of underground powerhouse. Surrounding rocks in the middle and upper part of the underground powerhouse are mainly in dry condition or unsaturated condition, which means the underground water can be effectively controled, the design of seepage control system is proper, and the drainage and pressure lowering effects are significant.

Besides, as illustrated in Fig.3 5, when the hydropower station enters into the stable operation stage, the drainage system above the free surface has little seepage control effects on reservoir water leakage. On the other side, it may play an important role in the drainage of rainfall recharge and local confined water. However, due to the disperse distribution and small amount of this part of water, the spacing of drainage holes of high elevation could be properly sparser.

\section{Conclusions}

Combining with the three-dimensional FE model of the underground powerhouse area, the SVA method was adopted in this paper to analyze the seepage field in Yagen II underground powerhouse, the main conclusions are as follows:

(1) In the operation condition, the seepage control effects of the seepage control system is significant. The underground water forms an obvious cone of depression in the surrounding rocks, and the transformer room is completely above the free surface, showing that the designed seepage control system is rational and proper.

(2) The drainage system above the free surface has little seepage control effects on reservoir water leakage. It may play an important role in the drainage of rainfall recharge and local confined water. Due to the disperse distribution and small amount of this part of water, the spacing of drainage holes of high elevation could be properly sparser.

\section{Acknowledgements}

This work was financially supported by the National Natural Science Foundation of China (51609019).

\section{References}

[1] Desai CS, Li GC. A residual flow procedure and application for free surface in porous media. Advances in Water Resources, 1983, 6(1): 27-35.

[2] Bathe KJ, Khoshgoftaar MR. Finite element free surface seepage analysis without mesh iteration. International Journal for Numerical and Analytical Methods in Geomechanics, 1979, 3(1): 13-22. 
[3] Zheng H, Liu DF, Lee CF, Tham LG. A new formulation of Signorini's type for seepage problems with free surfaces. International Journal for Numerical Methods in Engineering, 2005, 64(1): 1-16.

[4] Zhu YM, Zhang LJ. Solution to seepage field problem with the technique of improved drainage substructure. Chinese Journal of Geotechnical Engineering, 1997, 19(2): 69-76.

[5] Chen YF, Zhou CB, Zheng H. A numerical solution to seepage problems with complex drainage system. Computers and Geotechnics, 2008, 35(3): 383-393. 